\title{
Esverdeando a manufatura: dos fundamentos conceituais ao estudo de múltiplos casos
}

\author{
Charbel José Chiappetta Jabboura* \\ a*prof.charbel@gmail.com, charbel@feb.unesp.br, UNESP, Brasil
}

\begin{abstract}
Resumo
0 propósito deste artigo é analisar a inserção das questões ambientais no contexto da função produção/manufatura (ou operações), a qual é referenciada como a área organizacional que deve liderar a gestão ambiental empresarial. Para tanto, sistematizou-se o referencial teórico sobre o esverdeamento da área de produção, com implicações para o desenvolvimento de produto, processo, gestão da qualidade e logística. Tendo em vista que esse campo de pesquisa carece, ainda, de evidências empíricas, optou-se pela realização de quatro estudos de caso em empresas localizadas no Brasil. Constatou-se que o nível de maturidade da gestão ambiental dessas empresas tende a acompanhar o grau com que a questão ambiental é inserida nas subáreas de produção, principalmente no processo de desenvolvimento de produto. Não obstante, verificou-se, na maior parte dos casos, dificuldade dessas organizações em estruturar a inserção da dimensão ambiental nas atividades logísticas, desafio que pode ser superado com a adoção, por parte das empresas, dos modernos conceitos de green supply chain management. Os apontamentos finais ressaltam o distanciamento observado entre o que a literatura internacional apregoa e a realidade de empresas localizadas no Brasil no desafio de esverdear definitivamente as empresas manufatureiras.
\end{abstract}

Palavras-chave

Gestão ambiental. Manufatura. Desenvolvimento de produto. Sustentabilidade.

\section{Introdução}

Nunca foi tão acalorada a discussão sobre a necessidade de maior aproximação entre os temas produção/manufatura/operações e os pressupostos de gestão para a sustentabilidade, debate que provavelmente adquirirá magnitude ainda mais expressiva em futuro breve (Gunasekaran \& Ngai, 2012). Dentre os eixos de relacionamento entre produção e sustentabilidade, um dos mais críticos aborda o esverdeamento dessa área de gestão, isso é, sua relação com a gestão ambiental (Gunasekaran \& Spalanzani, 2011). A função produção é considerada o epicentro da gestão ambiental empresarial (Florida, 1996), mas como tal temática possui ainda contornos exploratórios de um contexto emergente, a literatura especializada carece de reflexões que contemplem de forma teórico-empírica as principais transformações que a função produção deve empreender para se tornar ambientalmente adequada. Nesse contexto, constata-se que um número crescente de autores vem envidando esforços para apresentar uma sistematização teórica sobre as principais transformações que devem ocorrer para a função produção tornar-se ambientalmente responsável (Gupta, 1995; Sarkis \& Rasheed, 1995; Sarkis, 2001; Angell \& Klassen, 1999; Jiménez \& Lorente, 2001; Gunasekaran \& Ngai, 2012), mas constata-se que esse debate carece de evidência empírica e, mais especificamente, de pesquisas que retratem a realidade organizacional brasileira.

Além disso, o contexto atual, de recrudescimento da regulamentação/diretrizes ambientais vem pressionando as organizações manufatureiras a se posicionarem mais pró-ativamente em termos ambientais (Koh et al., 2012). Assim sendo, e considerando a observação de que as questões ambientais estarão inextricavelmente desafiando o futuro da área produtiva (Bayraktar et al., 2007), pode-se dizer que essa pesquisa motiva-se para melhor entender: quais são as principais transformações e como elas vêm ocorrendo para 
que a função produção de empresas no Brasil se tornem ambientalmente mais adequadas?

Para lançar luzes sobre essa complexa problemática foi desenvolvida uma abordagem reflexiva sobre os seguintes temas: a interiorização da dimensão ambiental na empresa (seção 2); e a importância da função produção ambientalmente responsável (seção 3). Por fim, os pressupostos teóricos são confrontados com a realidade observada em empresas localizadas no Brasil, tendo como pano de fundo um planejamento metodológico (seção 4), apresentando-se os resultados obtidos (seção 5) e explorando-se conclusões e apontamentos para a continuidade da linha de investigação (seção 6).

\section{A interiorização da dimensão ambiental na empresa}

0 novo papel que as empresas devem desempenhar na construção do desenvolvimento sustentável gerou uma gama de pressões sobre a relação entre as firmas e a dimensão ambiental (Hoffman, 2005). Segundo Marcus \& Fremeth (2009), há um dever inerente à gestão organizacional de lidar adequadamente com a gestão ambiental, não havendo muita margem de inação para os gestores contemporâneos. De fato, as unidades produtivas estão sendo compelidas a inserirem a questão ambiental na formulação de seus planos estratégicos mais fundamentais (Stone, 2000). Essa integração entre negócios e meio ambiente recebe 0 nome de gestão ambiental (Backer, 2002), conceito que pode ser definido como a ponderação dos fatores ambientais em cada uma das decisões empresariais, incluindo-se as atividades de desenvolvimento de processos, produtos e planejamento estratégico (Barbieri, 2004).

Entretanto, apesar de a gestão ambiental na empresa se descortinar como uma temática cada vez mais aceita por teóricos e práticos, deve-se assumir que nem todas as empresas consideram a questão ambiental com nível idêntico de relevância (Polizelli et al., 2005). Em outras palavras, quer-se dizer que há diversos tipos de posicionamentos ambientais que uma dada empresa pode assumir. Por exemplo, Brío et al. (2001) concluíram, em pesquisa realizada com empresas espanholas, que o simples fato de uma empresa possuir um departamento de meio ambiente não significa que a questão ambiental tornou-se estratégica para ela. Esses posicionamentos diversos podem ser chamados de estágios da gestão ambiental na empresa e são tema de importantes pesquisas, já tornadas clássicas (Hunt \& Auster, 1990; Hart, 1995; Russo \& Fouts, 1997; Azzone et al., 1997; Buysse $\&$ Verbeke, 2003).
Geralmente, essas pesquisas indicam que o comportamento ambiental da empresa pode ser analisado por meio de três estágios distintos da gestão ambiental: (a) estágio reativo, em que os dirigentes organizacionais concebem a questão ambiental como epicentro de geração de custos desnecessários, como um modismo empresarial ingênuo; (b) estágio preventivo, em que as firmas evitam que os problemas ambientais ocorram, pois deduzem que tratar os efeitos da poluição é mais oneroso que evitar a geração dessa poluição; e (c) estágio em que a gestão ambiental se torna um fator estratégico para a empresa e passa a ser uma fonte de acesso aos mercados internacionais e geração de inovações sustentáveis, que serão expressivamente demandas em tempos vindouros (Rohrich \& Cunha, 2004).

No estágio em que a dimensão ambiental é considerada estratégica, as questões ambientais se tornam incumbência de todas as áreas de gestão, tais como recursos humanos (Boudreau \& Ramstad, 2005), finanças e marketing (Ginsberg \& Bloom, 2004). De fato, cada uma das áreas funcionais deve se transformar para incorporar a gestão ambiental. No bojo desse processo ocorre alinhamento das atividades funcionais aos objetivos de gestão ambiental (Backer, 2002). Na esteira desse processo, a literatura especializada ressalta a área de gestão da produção como aquela que mais necessita transformar-se para abarcar a variável ambiental (Buchholz, 1998). Com efeito, a performance ambiental da função produção condiciona o desempenho global da organização nesse aspecto. A próxima seção aborda as especificidades da interação entre a função produção e a gestão ambiental.

\section{A função produção e a dimensão ambiental}

Por sua natureza essencialmente transformadora, a função produção é aquela que apresenta maior potencial de geração ou mitigação dos impactos ambientais de uma firma (Corazza, 2003). Donaire (1999) afirma que os inputs do sistema produtivo estão diretamente relacionados, na maior parte dos casos, a um conjunto de recursos naturais explorados e os outputs, à geração de impactos ambientais que afetam a capacidade de suporte do planeta. Dessa forma, segundo Rothenberg et al. (2001), as decisões concernentes à gerência de sistemas produtivos possuem implicações sobre a relação entre empresa e meio ambiente natural, uma vez que é plausível assumir que as eventuais ineficiências de um dado sistema produtivo tendem a coincidir com os altos níveis de poluição registrados pela empresa. Como consequência, importantes pesquisas (Angell \& 
Klassen, 1999; Sarkis, 2001; Gupta, 1995; Hanna et al., 2000; Sarkis \& Rasheed, 1995; Pun, 2006; Rao \& Holt, 2005) vêm ressaltar a importância das empresas possuírem uma função produção ambientalmente responsável, definida como

[...] um sistema que integra as questões de desenvolvimento de produtos e processos no planejamento de controle da produção de forma a identificar, avaliar e gerenciar o fluxo produtivo, reduzindo ou eliminando os impactos ambientais gerados ao mesmo tempo em que maximiza a eficiência do sistema. (Handfield et al., 2001, p. 189).

Se essas transformações são atualmente aceitas como necessárias, os auspícios revelam que elas se colocarão de forma imperativa à função produção (Bayraktar et al., 2007).

A importância crescente da dimensão ambiental para a empresa a o reconhecimento da imprescindibilidade da função produção para esse tema tiveram como corolário a aceitação, por alguns estudiosos (Jiménez \& Lorente, 2001; Angell \& Klassen, 1999), da questão ambiental como um novo objetivo de desempenho da manufatura, ao lado das prioridades clássicas de custo, flexibilidade, qualidade e velocidade das entregas, e, portanto, da função produção como central para a gestão ambiental empresarial (Sarkis, 2001). Assim sendo, a dimensão ambiental, enquanto novo objetivo de desempenho da produção, fomenta suas congêneres competitivas, embora tais relações possam não ser completamente válidas para todas as empresas (Jabbour et al., 2012):

- Custo: 0 objetivo de desempenho de custo é potencializado pelas ações de gestão ambiental, que tendem a diminuir os desperdícios, estimular a descoberta de novas matérias-primas, induzindo a reutilização e reciclagem de materiais. Essas medidas ambientais tendem a reduzir o custo por unidade produzida em uma dada empresa;

- Rapidez: A gestão ambiental proativa possui como consequência a mitigação dos impactos ambientais e da eclosão de acidentes ambientais, contribuindo para que os prazos agendados para as entregas de produtos aos consumidores sejam cumpridos;

- Flexibilidade: A consideração da dimensão ambiental no desenvolvimento de produtos leva a empresa à prospecção de inovações ambientalmente adequadas, o que potencializa a flexibilidade da produção de uma dada empresa;

- Qualidade: A gestão ambiental proativa incrementa os objetivos da gestão da qualidade, que deve atender aos almejos dos consumidores ambientalmente responsáveis.

Apesar da clara relação entre a função produção e a gestão ambiental empresarial, raros são os trabalhos que tratam tal interação com profundidade, isto é, que ponderem as principais características da função produção ambientalmente responsável em suas subdivisões clássicas: (a) desenvolvimento de produto e processos; (b) logística; e (c) gestão da qualidade. Por isso, as próximas subsseções dedicam-se a esse debate.

\subsection{Desenvolvimento de produtos e processos ambientalmente mais sustentáveis}

\section{Conceitualmente,}

[...] desenvolver produtos consiste em um conjunto de atividades por meio do qual se busca, a partir das necessidades do mercado e das possibilidades e restrições tecnológicas, e considerando as estratégias competitivas e de produto da empresa, chegar às especificações de um produto e de seu processo de produção, para que a manufatura seja capaz de produzi-lo. (Rozenfeld et al., 2005, p. 3-4).

Esse processo se estende até o pós-lançamento do produto, objetivando-se obter informações que melhorem o projeto de um dado produto e o processo produtivo que é comum aos outros desenvolvimentos, o que fomenta a "aprendizagem pós-projeto" (Clark $\&$ Wheelwright, 1993). Sobre a complexidade do desenvolvimento de produtos, ele é um dos processos organizacionais mais complexos e que se relaciona com praticamente todas as demais funções empresariais.

0 desenvolvimento de produtos com elevado desempenho ambiental pode ser definido como a prática em que questões ambientais são integradas no processo de desenvolvimento de produto (Pujari et al., 2003). Entretanto, as atuais práticas de desenvolvimento de produto em empresas manufatureiras estão predominantemente pautadas nos modelos de lucratividade existentes, objetivando-se a geração de produtos com alta qualidade, baixo custo e elevada lucratividade. No desenrolar dessa lógica, a dimensão ambiental frequentemente passa a ser considerada um custo adicional e sua inserção necessária apenas quando imprescindível. Assim, os critérios ambientais tendem a ser tomados como secundários no processo de desenvolvimento de produtos (Kaebernick et al., 2003).

Tingström \& Karlsson (2006) propõem que o desenvolvimento de produto ambientalmente adequado seja compreendido por meio das principais fases de seu processo. De uma forma geral, as demandas dos consumidores ambientalmente conscientes e das necessidades ambientais pressionam a empresa a desenvolver um conhecimento ambiental relativo às perspectivas mercadológicas, de projeto do produto e de desenvolvimento de processos produtivos até o lançamento do produto. A utilização do produto e seu 
consequente descarte geram dois fluxos: (a) um de materiais, a serem reutilizados ou reciclados na fase de manufatura; e (b) outro de análise das consequências ambientais de cada fase, os quais fomentam um maior conhecimento sobre como o produto pode tornar-se ambientalmente mais adequado. Tipicamente, são duas técnicas que tendem a fornecer suporte à inserção de questões ambientais no processo de desenvolvimento de produtos: design para o meio ambiente (Design for Environment): consiste em um conjunto de diretrizes ambientais a ser considerado no processo de desenvolvimento de produtos, a fim de realizar-se a maior gama de melhorias ambientais possivel ainda na fase de projeto do produto (Handfield et al., 2001; Borchardt et al., 2012);

- Análise do ciclo de vida (Life Cycle Analysis): Avalia a tipologia e a quantidade dos inputs (energia, matéria-prima etc.) e dos outputs (emissões, rejeitos e outros impactos ambientais) no contexto que envolve desde o projeto do produto, passa por sua produção e culmina em seu descarte final (Fuller \& Ottman, 2004);

- Análise dos efeitos ambientais (Enviromental Effect Analysis): É uma variação do FMEA (Failure Mode Effect Analysis), contemplando-se a variável ambiental. 0 FMEA consiste na identificação de potenciais falhas, e seus riscos são avaliados por meio de índices. Com base nessa avaliação, são propostas ações de melhoria. Dessa forma, o EEA é um processo no qual são previstas situações em que o produto pode gerar impactos ambientais até então imprevistos, buscando-se opções para sua superação (Tingström \& Karlsson, 2006).

0 desenvolvimento de produto com elevado desempenho ambiental deve ser apoiado pela adoção de tecnologias ambientais durante o processo produtivo. Vachon \& Klassen (2007) indicam que as tecnologias ambientais podem ser amplamente definidas como a adoção de técnicas de design, equipamentos e procedimentos operacionais que limitam ou reduzem os impactos ambientais de produtos e serviços no ambiente natural. Kuehr (2007) empreendeu uma tipologia oriunda, principalmente, de sua percepção e experiência sobre o tema. Sua proposta é de que o conjunto das tecnologias ambientais pode ser divido em quatro categorias (Figura 1), a saber:

- Tecnologia de mensuração ambiental: Envolve ferramentas, instrumentos, equipamentos e sistemas de gestão da informação para mensuração e controle ambientais. Uma categoria desse tipo possui como objetivo fornecer uma gama confiável de opções para a tomada de decisões sobre a qualidade do meio ambiente; outra categoria objetiva fornecer à humanidade informações úteis na busca de alternativas ambientais como, por exemplo, para a falta de água e o aquecimento global. A tecnologia de

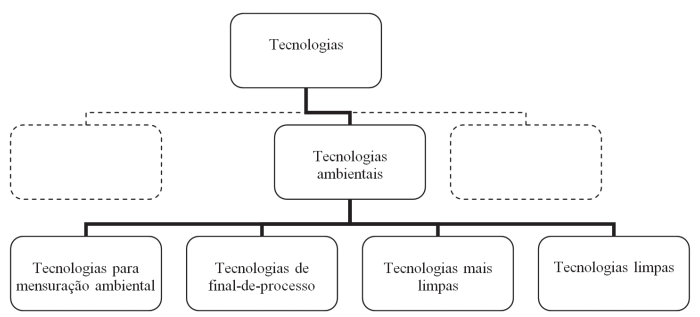

Figura 1. A tipologia das tecnologias ambientais. Fonte: adaptado de Kuehr (2007, p. 4).

mensuração ambiental contrasta com suas congêneres por não focar necessariamente a redução dos impactos produzidos pela humanidade sobre o ambiente natural, mas sim por subsidiar o entendimento de como o meio ambiente vem se alterando e quais são as melhores alternativas para minimizar os impactos dessas alterações sobre a perspectiva de qualidade de vida da população;

- Tecnologias de controle da poluição: Engloba o conjunto de processos e materiais que foram desenvolvidos para neutralizar os impactos gerados durante o ciclo produtivo, sem, necessariamente, implicar modificações nos processos originais. Em outras palavras, tais tecnologias apoiam o controle da poluição gerada em um determinado processo, sem alterá-lo completamente. Se por um lado tais tecnologias podem controlar a poluição, por outro podem gerar outros tipos de impactos ambientais, como, por exemplo, aumento no consumo de energia;

- Tecnologias mais limpas ou de prevenção da poluição: Diz respeito às modificações empreendidas para minimizar ou até mesmo eliminar qualquer efeito prejudicial que um processo pode gerar no meio ambiente. Diferem das tecnologias de controle da poluição por requererem uma perspectiva holística de como podem ser reduzidos os impactos ambientais de um processo ou produto;

- Tecnologias ambientais de impacto nulo: Tange às tecnologias que, de fato, não geram impacto algum durante seu processo de desenvolvimento e utilização. Dentro de uma perspectiva pontual, essas tecnologias podem ser observadas no campo da biotecnologia, mas no contexto de um ciclo produtivo completo sua existência é considerada utópica.

\subsection{Gestão da qualidade ambiental}

A busca da qualidade total tornou-se um dos pilares que garantem a sobrevivência empresarial no atual cenário global, altamente competitivo, dada a globalização dos mercados. Entretanto, principalmente nos mercados norte-americano e europeu, a qualidade dos produtos e serviços não é mais um critério ganhador de pedidos, mas sim qualificador (Martins \& Nascimento, 1998). A esse 
respeito, Daroit \& Nascimento (1998) alertam que uma empresa produtora de excelente manufaturado ou serviço, mas cuja produção ou operação cause impactos ambientais negativos, pode ter sua posição no mercado afetada, pois vários agentes podem vir a exercer pressão para que ela reverta o problema. Ainda segundo esses autores, tal situação gera custos extras elevados, pois o período requerido para sanar um problema ambiental é normalmente longo, fato que inviabiliza a permanência da organização no mercado. Isso ocorre porque as questões ambientais estão se tornando um novo objetivo de desempenho da função produção (Jiménez \& Lorente, 2001).

Segundo Aboulnaga (1998), a interiorização da variável ambiental na qualidade total está auxiliando as organizações a melhorarem continuamente seu desempenho ambiental e sua responsabilidade social, além de contribuir para o aumento da produtividade, geração de inovações baseadas em tecnologias mais limpas e aumento da competitividade. A integração entre variável ambiental e TQM é tratada pela literatura especializada pelo termo TQEM (Brío et al., 2001; Lawrence et al., 1998), isto é, Total Quality Environmental Management, a qual pode ser desenvolvida a partir de um sistema de gestão ambiental, aplicando-se a esse a filosofia que rege a TQM enfocando o meio ambiente. A expressão TQEM foi criada pelo Global Environmental Management Initiative (GEMI), uma organização não governamental criada por um grupo de 21 empresas multinacionais (Barbieri, 2004). A sinergia entre gestão da qualidade e desempenho ambiental foi também comprovada por recente pesquisa de Zhu et al., (2013).

\subsection{Sistema logístico ambientalmente responsável}

A origem do termo logística é bélica e advém da palavra loger, que no francês significa acomodar e suprir tropas no campo de batalha. Segundo Novaes (2001, p. 36),

[...] logística é o processo de planejar, implementar e controlar de maneira eficiente o fluxo e a armazenagem de produtos, bem como os serviços e informações associados, cobrindo desde o ponto de origem até o ponto de consumo, com o objetivo de atender aos requisitos do consumidor.

Segundo Wu \& Dunn (1995), a gestão ambiental empresarial torna-se potencialmente falaciosa sem a contribuição das atividades logísticas para o alcance de uma performance superior. Ainda segundo esse trabalho clássico, o desafio das atividades logísticas é integrar a dimensão ambiental ao contexto da tomada de decisão dos gestores de logística (Figura 2). Nesse,

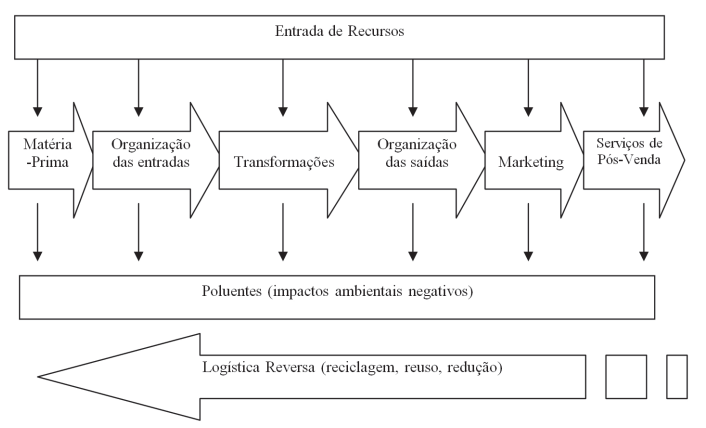

Figura 2. Decisões logísticas que devem considerar a dimensão ambiental. Fonte: adaptado de Wu \& Dunn (1995, p. 34).

Lai et al. (2013) afirmam que é importante avançar em propostas de mensuração do impacto ambiental e do esverdeamento dos modais de transporte logístico. González-Benito \& González-Benito (2006) afirmam que a quase totalidade das melhorias ambientais que podem ser empreendidas por uma dada firma depende da contribuição das atividades logísticas para se efetivarem. Ainda nesse sentido, Lin, Jones e Hsieh (2001) afirmam que a análise da gestão ambiental empresarial deve contemplar a inserção de aspectos ambientais nas atividades de logísticas.

Como indicam Wu \& Dunn (1995), os agrupamentos de decisões sobre logística que estão diretamente relacionados com a responsabilidade ambiental são:

- Aquisição de matérias-prima: Esse grupo envolve decisões sobre todos os recursos que servirão de inputs ao processo produtivo. Assim, faz-se mister que a logística ambientalmente responsável utilize matérias-primas ecologicamente adequadas, por meio da reavaliação de fornecedores e materiais utilizados;

- Organização das entradas. Importa tomar as decisões ambientalmente mais adequadas concernentes ao modo como os inputs serão transportados, armazenados e conduzidos no momento adequado ao processo de transformação;

- Transformação: Discute como as entradas serão conduzidas para o processo de transformação. Envolve decisões de transporte, embalagens utilizadas e consumo de energia;

- Organização das saídas: Nessa fase, organizam-se como os produtos acabados serão armazenados e sua distribuição planejada. A principal diferença entre a organização das entradas e a organização das saídas é que essa última trata de produtos acabados;

- Marketing: As decisões de marketing afetam as estratégias de logística, sendo a recíproca verdadeira. As decisões do composto de marketing, ligadas ao preço, distribuição, produto e promoção deverão ser ambientalmente corretas (Ginsberg \& Bloom, 2004); 
- Serviços de pós-venda: Nessa fase são planejadas as atividades de instalação, reparo, manutenção ou troca de produtos vendidos anteriormente.

De fato, a integração da dimensão ambiental no contexto das atividades logísticas é de extrema complexidade, o que demanda que os gestores dessa área estejam cientes da estratégia ambiental da firma e de como podem colaborar proativamente com tal processo (González-Benito \& González-Benito, 2006), mas para tanto deverão estar preparados para avaliar o nível de maturidade com que suas atividades logísticas vêm contribuindo para a gestão ambiental empresarial (Hervani et al., 2005; Zhu et al., 2005) e, em um contexto mais amplo, como a cadeia de fornecedores pode se tornar ambientalmente adequada (Simpson \& Power, 2005). Assim, passa-se a uma perspectiva mais ampla, de que as empresas ambientalmente proativas estão comprometidas com o esverdeamento de toda a cadeia de suprimentos a que pertence, dando origem ao conceito Green Supply Chain Management (Zhu et al., 2005). Entretanto, para o esverdeamento da cadeia de suprimentos como um todo, as empresas focais e a colaboração entre os integrantes da cadeia tornam-se fundamentais, sendo também relevante o papel das regulamentações/ diretrizes ambientais internacionais (Koh et al., 2012). Para lançar luzes sobre a evidência empírica desse complexo processo planejou-se a realização de um estudo de múltiplos casos.

\section{Materiais e métodos da pesquisa}

Esta pesquisa vale-se do método do estudo de caso, o estudo de um dado fenômeno, passado ou atual, observado por meio de múltiplas perspectivas e em seu contexto original (Leonard-Barton, 1990), no qual o pesquisador não manipula os sujeitos envolvidos e não influencia a configuração do fenômeno (Hoppen et al., 1996), geralmente contemporâneo à sociedade (Cauchick-Miguel, 2007). Optou-se pelo estudo de casos múltiplos (Cunningham, 1997). Foi selecionado um conjunto de empresas que atendessem, plenamente, aos requisitos e recomendações para a composição da amostra. A quantidade de empresas revelou-se próxima à adotada em pesquisas similares (Boiral, 2002; Mross \& Rothenberg, 2007), além de oportuna para o modelo conceitual previamente sistematizado. Observando-se as recomendações para o planejamento da amostra em estudo de casos (Voss et al., 2002), foram selecionadas quatro empresas localizadas no Brasil, chamadas de Alfa, Beta, Gama e Delta, todas elas manufatureiras, categoria que tende a gerar grandes impactos ambientais por envolver processos intensivos de transformação de inputs em outputs (Sarkis, 2001). A coleta de dados perdurou entre 2006 e 2007. Foram coletados dados por meio dos métodos: entrevistas, observação e análise documental. As entrevistas foram conduzidas junto a representantes das áreas de gestão ambiental e produção, buscando-se respondentes experientes e diversos. Seguiu-se o padrão de quantidade de áreas analisadas e de conjunto de entrevistados utilizado em pesquisas com validade internacional (Boiral, 2002). 0 Tabela 1 sintetiza a caracterização de cada empresa, bem como a dinâmica do processo de coleta de dados empreendido. Depois de coletados, os dados foram confrontados (entrevistas, documentos e observações) e agrupados segundo as principais variáveis desta pesquisa: (a) gestão ambiental; (b) desenvolvimento de processos e produtos; (c) logística; e (d) gestão da qualidade. $\mathrm{Na}$ sequência, as informações sistematizadas foram confrontadas durante as tentativas de entendimento do fenômeno sob análise.

\section{Resultados}

A seguir apresentam-se as evidências empíricas dos casos Alfa, Beta, Gama e Delta.

\subsection{Considerações sobre a gestão ambiental das empresas pesquisadas}

Nas quatro empresas, as atividades de gestão ambiental encontram-se formalmente estruturadas como uma área na estrutura organizacional. Nas empresas Alfa, Beta e Gama há a adoção de um sistema integrado de gestão, o qual vincula a gestão da qualidade aos aspectos ambientais, de saúde e segurança do trabalho. Por isso, a gestão ambiental reporta-se à gerência da qualidade. $\mathrm{Na}$ empresa Delta, a área de gestão ambiental reporta-se diretamente à gerência da qualidade e não é adotado sistema integrado de gestão. Nos quatro casos, a gestão ambiental é liderada por funcionários com grande experiência profissional nessas empresas. Nas empresas Beta e Delta, os gerentes ambientais são provenientes das áreas de gestão da qualidade; na empresa Alfa, o responsável é oriundo da área de Pesquisa \& Desenvolvimento (P\&D); na empresa Gama, é proveniente da área de Segurança do Trabalho. A seleção de pessoal com experiência na dinâmica organizacional foi enfatizada como necessária para respaldar a inserção das questões ambientais na organização.

As quatro empresas estudadas apresentam similaridades quanto aos principais eventos da trajetória de seu gerenciamento ambiental. Nas quatro empresas, grande atenção é voltada ao aumento da produtividade dos recursos naturais básicos, principalmente relacionados à racionalização do consumo de água e energia. Grande esforço é igualmente orientado para o controle da poluição, com destaque para a construção de estações de 
Tabela 1. Breve caracterização das empresas pesquisadas e da dinâmica do processo de coleta de dados.

\begin{tabular}{|c|c|c|c|c|c|}
\hline \multirow{2}{*}{ Empresa } & \multirow{2}{*}{\multicolumn{2}{|c|}{ Caracterização }} & \multicolumn{3}{|c|}{ Dinâmica da coleta de dados } \\
\hline & & & Entrevistas & Documentos & Observação \\
\hline Alfa & & $\begin{array}{l}\text { Empresa do } \\
\text { setor de bens de } \\
\text { consumo não } \\
\text { duráveis líder de } \\
\text { mercado. }\end{array}$ & $\begin{array}{l}\text { - Entrevista com o responsável pela área } \\
\text { de gestão ambiental e coordenador do } \\
\text { sistema de gestão ambiental 1SO } 14001 \\
\text { da empresa. } \\
\text { - Cinco entrevistados das áreas de gestão } \\
\text { da qualidade, logística, manufatura e } \\
\text { desenvolvimento de produtos. } \\
\text { - Entrevista com o gerente de P\&D. }\end{array}$ & $\begin{array}{l}\text { Diversos documentos sobre a } \\
\text { história da empresa. } \\
\text { - Código de conduta corporativo. } \\
\text { - Documentos sobre a gestão } \\
\text { ambiental na empresa e sobre } \\
\text { sua política ambiental. } \\
\text { - Balanços socioambientais (2005 } \\
\text { e 2006). } \\
\text { - Folders e outros materiais sobre } \\
\text { gestão ambiental divulgados } \\
\text { para os funcionários. } \\
\text { Documentos digitais obtidos na } \\
\text { World Wide Web. }\end{array}$ & $\begin{array}{l}\text { - Três visitas } \\
\text { técnicas. } \\
\text { - Visitas para a } \\
\text { realização das } \\
\text { entrevistas. } \\
\text { - Uma visita junto } \\
\text { ao centro de P\&D } \\
\text { da empresa. }\end{array}$ \\
\hline Beta & & $\begin{array}{l}\text { Empresa do setor } \\
\text { metal-mecânico } \\
\text { pertencente } \\
\text { a um grupo } \\
\text { automotivo. }\end{array}$ & $\begin{array}{l}\text { - Entrevista com o responsável pela } \\
\text { comunicação corporativa. } \\
\text { - Entrevista com o gerente ambiental, } \\
\text { coordenador do sistema de gestão } \\
\text { ambiental } 1 S 0 \text { 14001. } \\
\text { - Quatro entrevistados das áreas de gestão: } \\
\text { qualidade, logística, manufatura e } \\
\text { desenvolvimento de produtos. }\end{array}$ & $\begin{array}{l}\text { Documentos sobre a história da } \\
\text { empresa. } \\
\text { - Guia dos princípios corporativos. } \\
\text { Folders e material de educação } \\
\text { ambiental fornecidos aos } \\
\text { funcionários. } \\
\text { - Documentos digitais obtidos na } \\
\text { World Wide Web. }\end{array}$ & $\begin{array}{l}\text { - Uma visita técnica. } \\
\text { - Visitas para a } \\
\text { realização das } \\
\text { entrevistas. }\end{array}$ \\
\hline Gama & & $\begin{array}{l}\text { Empresa do } \\
\text { setor de bens de } \\
\text { consumo não } \\
\text { duráveis líder em } \\
\text { seu mercado e } \\
\text { conhecida por } \\
\text { seu potencial } \\
\text { inovador. }\end{array}$ & $\begin{array}{l}\text { Entrevistas com o gerente de EHS } \\
\text { (Environmental, Health and Safety), } \\
\text { inclusive } 15014001 . \\
\text { - Entrevistas com os responsáveis } \\
\text { pelas áreas de gestão da qualidade, } \\
\text { desenvolvimento de processos, logística } \\
\text { e P\&D. } \\
\text { - Entrevista junto a funcionário da área } \\
\text { de P\&D. }\end{array}$ & $\begin{array}{l}\text { Principalmente, documentos } \\
\text { obtidos na World Wide Web } \\
\text { sobre a história da empresa, } \\
\text { política de gestão de pessoas e } \\
\text { de gestão ambiental. } \\
\text { - Apresentações de resultados } \\
\text { ambientais apresentados } \\
\text { ao público interno (MS } \\
\text { PowerPoint). } \\
\text { - Organograma da área ambiental. }\end{array}$ & $\begin{array}{l}\text { - Uma visita técnica. } \\
\text { - Visitas para a } \\
\text { realização das } \\
\text { entrevistas. }\end{array}$ \\
\hline Delta & & $\begin{array}{l}\text { Empresa do setor } \\
\text { metalúrgico, líder } \\
\text { no mercado em } \\
\text { que atua. }\end{array}$ & $\begin{array}{l}\text { - Entrevista com o gerente de uma unidade } \\
\text { de negócio. } \\
\text { Entrevistas com os responsáveis pelas } \\
\text { áreas de gestão da qualidade, logística } \\
\text { e de desenvolvimento de processos e } \\
\text { produtos. }\end{array}$ & $\begin{array}{l}\text { Documentos sobre a história da } \\
\text { empresa. } \\
\text { - Código de ética da empresa. } \\
\text { Documentos sobre gestão } \\
\text { ambiental e gestão de recursos } \\
\text { humanos. } \\
\text { - Documentos digitais obtidos na } \\
\text { World Wide Web. }\end{array}$ & $\begin{array}{l}\text { - Duas visitas } \\
\text { técnicas. } \\
\text { - Visitas para a } \\
\text { realização das } \\
\text { entrevistas nas } \\
\text { duas plantas da } \\
\text { empresa. }\end{array}$ \\
\hline
\end{tabular}

tratamento de efluentes no conjunto de empresas. Entretanto, apenas nas empresas Alfa e Gama a maior parcela dos resíduos segue para reaproveitamento, tornando-se novos inputs do processo produtivo.

A criação das áreas de gestão ambiental remonta à certificação ambiental para as empresas Beta e Delta. A empresa Alfa possuía uma área de gestão ambiental anterior à certificação e há evidências de que a preocupação ambiental remonta à década de 1990, quando a empresa obteve a mais prestigiosa certificação de garantia de manejo sustentável de sua reserva florestal fornecedora de matéria-prima. A empresa Gama já possuía um sistema de gestão ambiental não certificado em operação desde a década de 1980. Em todas as empresas, a certificação ISO 14001 foi enfatizada como importante para sistematizar os esforços em meio ambiente, sendo esse, pois, um dos principais marcos da gestão ambiental para elas, mas na empresa Gama destaca-se a implementação do programa Análise do Ciclo de Vida, que objetiva avaliar impactos e melhorias ambientais durante o ciclo de vida de cada um de seus produtos.

A certificação ISO 14001 foi apontada como importante evento de gestão ambiental dessas empresas, entretanto constatam-se diferenças na intensidade dos elementos que motivam sua adoção. Invariavelmente, o conjunto de casos revela que a adoção da norma é motivada por: (a) sistematização do aumento da produtividade de insumos básicos; (b) redução de multas ambientais; e (c) garantia de acesso ao mercado externo. Além dessas razões, Alfa adotou a ISO 14001 para melhorar sua imagem junto à sociedade, para atrair consumidores conscientes e explorar, ainda que de forma não sistemática, oportunidades de inovação em produtos e processos. $\mathrm{Na}$ empresa Beta, apesar da melhoria da imagem e da possibilidade de atrair consumidores responsáveis terem motivado a adoção, a organização não vem adotando práticas para tanto. Grande pluralidade de motivações induziu a empresa Gama a adotar a 
certificação ISO 14001, diferenciando-se das demais por: (a) buscar aumento da valorização das ações, o que culminou com a inclusão da empresa no Down Jones Sustainability Index; e (b) explorar de forma sistematizada oportunidades de inovação com elevado desempenho ambiental. Por essas razões, Beta e Gama podem ser classificadas no estágio reativo de gestão ambiental, a empresa Alfa pode ser classificada no estágio preventivo e a empresa Gama no estágio proativo. 0 Tabela 2 sistematiza as motivações para a adoção da certificação ISO 14001 nesses casos.

\subsection{A inserção da questão ambiental na função produção das empresas pesquisadas}

A função produção foi sistematicamente apontada como área de gestão crítica para a incorporação das questões ambientais na organização e obtenção da consequente melhoria do desempenho ambiental. Entretanto, constatou-se que as organizações possuem diferentes expectativas quanto aos efeitos da inserção da dimensão ambiental entre as prioridades competitivas da estratégia de produção. Enquanto espera-se a redução de custos em todas as empresas pesquisadas, principalmente pelo aumento da produtividade dos insumos naturais e pela redução do montante despendido com eventuais multas de cunho ambiental, constata-se que apenas nas empresas Alfa e Gama a dimensão ambiental é tratada como um fator de qualidade de seus produtos, principalmente por consumidores situados no mercado externo ao brasileiro. Na empresa Gama é visível o tratamento da dimensão ambiental como variável relevante para a renovação do mix de produtos, no qual a geração de inovações em produtos com elevado desempenho ambiental vem gerando o acesso a novos mercados ou a exploração de novos nichos de consumidores em mercados em que a empresa já atua. Não foi identificada preocupação da influência das questões ambientais sobre o desempenho das entregas nesses casos (Tabela 3).
De uma forma geral, as práticas de gestão ambiental nos casos sob análise iniciaram-se na área produtiva, principalmente no campo do desenvolvimento de processos. lsso se deve ao fato de que é durante o processo produtivo que tendem a ser gerados os impactos ambientais passíveis de penalidade legal, uma vez que a inserção da questão ambiental nos produtos, qualidade e logística raras vezes é objeto de matéria legal ambiental. Como consequência, as quatro empresas adotam sofisticados sistemas de final de processo, principalmente com a adoção de estações de tratamento de efluentes.

As tecnologias de mensuração ambiental são adotadas de forma peculiar, dependendo do contexto próprio de cada organização. A empresa Alfa adota hidrômetros e outras formas de mensuração da produtividade dos recursos naturais, uma vez que há um programa formal para esse fim. A empresa Beta, por localizar-se em área de potencial risco ambiental, adota tecnologia de mensuração da qualidade da água subterrânea, localizada em diversos pontos geográficos da propriedade. A empresa Gama possui tecnologias para a estimação da quantidade de gases causadores do efeito estufa emitidos durante seu processo produtivo, uma vez que a redução desse índice é uma das metas da organização. A adoção de tecnologias mais limpas e de prevenção da poluição é constatada na empresa Alfa, a fim de aumentar a ecoeficiência dos recursos, sistematicamente crescente na empresa Gama, por incentivo de seu conceituado programa de prevenção da poluição, o qual apregoa a utilização de solventes não orgânicos, cuja reação

Tabela 3. Contribuições da dimensão ambiental para a competitiva da produção.

\begin{tabular}{ccccc}
\hline \multirow{2}{*}{ Caso } & \multicolumn{3}{c}{ Prioridades competitivas da estratégia de produção } \\
\cline { 2 - 4 } & Custo & Rapidez & Flexibilidade & Qualidade \\
\hline Alfa & $\mathrm{X}$ & & & $\mathrm{X}$ \\
Beta & $\mathrm{X}$ & & $\mathrm{X}$ \\
Gama & $\mathrm{X}$ & & $\mathrm{X}$ \\
Delta & $\mathrm{X}$ & & & \\
\hline
\end{tabular}

Tabela 2. Sistematização das motivações para a adoção da certificação ISO 14001 nos casos pesquisados.

\begin{tabular}{|c|c|c|c|c|c|c|c|}
\hline \multirow[b]{2}{*}{ Caso } & \multicolumn{7}{|c|}{ Motivações para a adoção do sistema de gestão ambiental } \\
\hline & $\begin{array}{l}\text { Aumento da } \\
\text { produtividade } \\
\text { dos insumos } \\
\text { básicos }\end{array}$ & $\begin{array}{c}\text { Redução } \\
\text { de multas } \\
\text { ambientais }\end{array}$ & $\begin{array}{c}\text { Acesso ao } \\
\text { mercado } \\
\text { externo }\end{array}$ & $\begin{array}{c}\text { Melhoria } \\
\text { da imagem } \\
\text { organizacional }\end{array}$ & $\begin{array}{c}\text { Atração e } \\
\text { retenção de } \\
\text { consumidores }\end{array}$ & $\begin{array}{c}\text { Valorização } \\
\text { das ações da } \\
\text { empresa }\end{array}$ & $\begin{array}{l}\text { Oportunidade } \\
\text { de inovação }\end{array}$ \\
\hline Alfa & & & & & & & \\
\hline Beta & & & & & & & \\
\hline Gama & & & & & & & \\
\hline Delta & & & & & & & \\
\hline
\end{tabular}


tende a liberar menos gases geradores do efeito estufa que seus congêneres orgânicos.

A inclusão dos critérios ambientais no desenvolvimento de produtos fornece importantes informações sobre as diferenças da gestão ambiental nessas empresas. De uma forma geral, três comportamentos são observados: (a) da empresa Alfa, que, apesar da crescente inserção da questão ambiental nesse processo, carece de metodologias e técnicas para sistematização, o que conduz a empresa à realização de melhorias pontuais; (b) das empresas Beta e Delta, as quais não possuem iniciativas próprias de desenvolvimento de produtos, seja porque exploram apenas melhorias ambientais de componentes produzidos por fornecedores, seja porque a principal melhoria no desempenho ambiental do produto foi motivada exclusivamente por força legal; (c) da empresa Gama, que vem inserindo de forma crescente e sistemática as questões ambientais no desenvolvimento de produtos.

Essas diferenças no processo de desenvolvimento de produtos podem ser constatadas por meio de exemplos práticos do projeto de desenvolvimento de cada empresa:

- Alfa não possui formas sistematizadas para a inclusão de questões ambientais no desenvolvimento de produtos. Essa inserção é dependente da sensibilização pessoal do designer, que tende a realizar melhorias incrementais. Por exemplo, a embalagem de um dos produtos da empresa teve alterada sua composição de PVC para material PET reciclado. Nesse caso, o designer sugeriu a mudança para melhorar o potencial de reciclagem da embalagem, uma vez que a presença de PVC na reciclagem demanda incorporação de aditivos que encarecem o processo;

- Beta obteve incremento no desempenho ambiental de seus produtos devido à exploração de melhorias ambientais em componente fornecido por fornecedor, isto é, não inseriu diretamente critérios ambientais em seu processo de desenvolvimento de produto. 0 exemplo é o da adoção do sistema de injeção bicombustível, ou flex, que foi liderada por um dos fornecedores da empresa Beta. A organização adotou a inovação para acompanhar as empresas concorrentes, cuja adoção já havia se iniciado.

- Gama instituiu em 2001 um projeto de Análise do Ciclo de Vida dos mais de 3 mil produtos que fabrica. A meta é analisar, sistematizar e criar condições para reduzir o impacto ambiental gerado por tais produtos até 2010 , a qual se tornou uma das mais desafiadoras para a organização. Um exemplo de sucesso é observado no processo de fabricação de material esponjoso, onde a união de duas partes do produto era realizada mediante utilização de processo intensivo com solventes geradores de gases do efeito estufa. A utilização de solventes foi identificada como geradora de impactos ambientais e substituída por solventes à base de água, reduzindo-se 100\% das emissões antes geradas;

- Delta não possui forma sistemática de inclusão da questão ambiental no processo de desenvolvimento de produtos e vê tal potencial como limitado. A principal transformação nesse sentido ocorreu por força legal, quando vários países do mundo ratificaram o Protocolo de Montreal, na década de 1990, o qual proibiu a utilização do fluido refrigerante CFC nos países membros, países sede de clientes que importam cerca de $70 \%$ da produção anual de Delta. A escolha da empresa foi utilizar o fluido refrigerante tetra-flúor-etano, desconsiderando-se $\mathrm{o}$ isobutano enquanto alternativa, embora apresente melhoria significativa no desempenho ambiental (não agride a camada de ozônio e possui reduzido poder de aquecimento global) mas incorre em maiores custos de produção, por apresentar menor capacidade frigorífica que seus similares.

Em todos os casos, a experiência prévia obtida durante o processo de certificação da qualidade ISO 9001 foi importante para a obtenção da certificação ISO 14001, em termos de adequação aos requisitos e manutenção. Nos casos das empresas Alfa, Beta e Gama, a implantação de um sistema integrado de gestão possibilitou que a questão ambiental fosse discutida de forma integrada à gestão da qualidade, segurança e saúde do trabalhador. Na empresa Gama, várias técnicas provenientes da gestão da qualidade vêm apoiando a gestão ambiental, tais como Seis Sigma, 5S e a análise de não conformidades na causa-raiz. Menor interface foi observada em termos de integração de critérios ambientais na gestão da logística. De uma forma geral, todas as empresas apresentam atividades simples de logística reversa, com o retorno de embalagens de insumos aos fornecedores. As motivações para essa prática e para a intensidade de sua adoção, porém, variam, e nas empresas Alfa, Beta e Delta a principal motivação não é a melhoria do desempenho ambiental. A empresa Gama apresenta a exploração de uma maior gama de decisões sobre a logística ambientalmente adequadas. Estão envolvidas nesse conjunto decisões quanto à armazenagem de insumos e produtos acabados, para evitar poluição e acidentes ambientais. Outro exemplo é o desenvolvimento de um composto líquido que evita que as cargas de minérios levantem poeira durante o transporte pelas rodovias, 0 que contribui para diminuir a poluição do ar. 0 Tabela 4 sistematiza as principais características da inserção da questão ambiental nas práticas da função produção. A empresa Gama possui procedimentos mais avançados para essa inclusão quando comparada às demais empresas, principalmente por possuir procedimentos que sistematizam o relacionamento entre critérios ambientais, desenvolvimento de processos, gestão da qualidade, gestão da logística e, principalmente, o processo de desenvolvimento de produtos. Em segundo plano, 
Tabela 4. Características da inclusão da dimensão ambiental nas práticas da função produção para os casos pesquisados.

\begin{tabular}{|c|c|c|c|c|}
\hline Caso & Desenvolvimento de produtos & Desenvolvimento de processos & Gestão da qualidade & Gestão da logística \\
\hline Alfa & $\begin{array}{l}\text { - Critérios ambientais não são } \\
\text { considerados sistematicamente. } \\
\text { - A preocupação básica é atender } \\
\text { os padrões toxicológicos } \\
\text { estipulados pela legislação } \\
\text { ambiental internacional, com } \\
\text { ênfase nas normas dos EUA } \\
\text { e da UE. } \\
\text { - O desenvolvimento de produtos } \\
\text { com elevado desempenho } \\
\text { ambiental é casual, pois tende } \\
\text { a depender do comportamento } \\
\text { do designer. } \\
\text { - Alteração típica é a busca } \\
\text { pela inclusão de componentes } \\
\text { reciclados nos produtos. }\end{array}$ & $\begin{array}{l}\text { - Critérios ambientais são } \\
\text { considerados sistematicamente. } \\
\text { - Tecnologias de mensuração } \\
\text { ambiental para monitoramento } \\
\text { da produtividade dos insumos } \\
\text { ambientais essenciais, como } \\
\text { água e energia. } \\
\text { - Tecnologias de final de } \\
\text { processo, físicas e químicas, } \\
\text { para o tratamento de resíduos. } \\
\text { - Tecnologias de prevenção da } \\
\text { poluição. }\end{array}$ & $\begin{array}{l}\text { - Critérios ambientais são } \\
\text { considerados sistematicamente. } \\
\text { - Sistema integrado de gestão. } \\
\text { - Utilização da experiência prévia } \\
\text { obtida na gestão da qualidade } \\
\text { para liderar a gestão ambiental. } \\
\text { - Ferramentas da gestão da } \\
\text { qualidade não apoiam a gestão } \\
\text { ambiental sistematicamente. }\end{array}$ & $\begin{array}{l}\text { - Critérios ambientais } \\
\text { não são considerados } \\
\text { sistematicamente. } \\
\text { - Retorno de produtos } \\
\text { para a destruição ou } \\
\text { retrabalho. }\end{array}$ \\
\hline Beta & $\begin{array}{l}\text { - Critérios ambientais não são } \\
\text { considerados sistematicamente. } \\
\text { - A melhoria do desempenho } \\
\text { ambiental dos produtos é } \\
\text { frequentemente obtida por } \\
\text { pressão exercida sobre os } \\
\text { fornecedores, no sentido de } \\
\text { eles produzirem componentes } \\
\text { com desempenho ambiental } \\
\text { elevado. }\end{array}$ & $\begin{array}{l}\text { - Critérios ambientais são } \\
\text { considerados sistematicamente. } \\
\text { - Tecnologias de mensuração } \\
\text { ambiental para o } \\
\text { monitoramento da qualidade } \\
\text { da água subterrânea. } \\
\text { - Tecnologias de final de } \\
\text { processo para a recuperação e } \\
\text { tratamento de resíduos. } \\
\text { - Tecnologias de prevenção da } \\
\text { poluição. }\end{array}$ & $\begin{array}{l}\text { - Critérios ambientais são } \\
\text { considerados sistematicamente. } \\
\text { - Sistema integrado de gestão. } \\
\text { - Utilização da experiência prévia } \\
\text { obtida na gestão da qualidade } \\
\text { para liderar a gestão ambiental. } \\
\text { - Ferramentas da gestão da } \\
\text { qualidade não apoiam a gestão } \\
\text { ambiental sistematicamente. }\end{array}$ & $\begin{array}{l}\text { - Critérios ambientais } \\
\text { não são considerados } \\
\text { sistematicamente. } \\
\text { - } \text { Logística reversa entre } \\
\text { a empresa e alguns de } \\
\text { seus fornecedores de } \\
\text { componentes, para o } \\
\text { retorno de embalagens } \\
\text { daquela para esses. }\end{array}$ \\
\hline Gama & $\begin{array}{l}\text { - Critérios ambientais são } \\
\text { considerados sistematicamente. } \\
\text { - Utilização de metodologias de } \\
\text { desenvolvimento de produtos } \\
\text { com elevado desempenho } \\
\text { ambiental: DfE, LCA e EEA. } \\
\text { - Todas as famílias de produtos } \\
\text { serão reanalisadas por meio de } \\
\text { LCA e EEA até } 2010 . \\
\text { - Novos produtos são } \\
\text { autorizados após aval da área } \\
\text { de toxicologia. } \\
\text { - Prospecção de fornecedores } \\
\text { com capacidade para } \\
\text { acompanhar a crescente } \\
\text { inserção das questões } \\
\text { ambientais no desenvolvimento } \\
\text { de produtos. }\end{array}$ & $\begin{array}{l}\text { - Critérios ambientais são } \\
\text { considerados sistematicamente. } \\
\text { - Tecnologias de mensuração } \\
\text { ambiental para monitorar a } \\
\text { produtividade dos insumos } \\
\text { ambientais essenciais, como } \\
\text { água e energia. } \\
\text { - Tecnologias de mensuração } \\
\text { ambiental para monitoramento } \\
\text { da emissão de gases poluentes } \\
\text { durante o processo produtivo. } \\
\text { - Tecnologias de final de } \\
\text { processo para a recuperação de } \\
\text { solventes. } \\
\text { - Tecnologias de prevenção da } \\
\text { poluição que sejam isentas de } \\
\text { solventes orgânicos. }\end{array}$ & $\begin{array}{l}\text { - Critérios ambientais são } \\
\text { considerados sistematicamente. } \\
\text { - Sistema integrado de gestão. } \\
\text { - Utilização da experiência prévia } \\
\text { obtida na gestão da qualidade } \\
\text { para liderar a gestão ambiental. } \\
\text { - Utilização de técnicas de } \\
\text { gestão da qualidade orientadas } \\
\text { para o meio ambiente, } \\
\text { como: (a) índices de não } \\
\text { conformidade; (b) gestão } \\
\text { da melhoria contínua do } \\
\text { desempenho ambiental. } \\
\text { - Esforços de melhoria da } \\
\text { qualidade vinculados à } \\
\text { melhoria dos indices de } \\
\text { desempenho ambiental: } \\
\text { reduzindo emissões, resíduos e } \\
\text { consumo de insumos. }\end{array}$ & $\begin{array}{l}\text { - Critérios ambientais } \\
\text { são considerados } \\
\text { sistematicamente. } \\
\text { - Influência dos critérios } \\
\text { ambientais nas } \\
\text { decisões logísticas de: } \\
\text { - (a) forma de transporte } \\
\text { de produtos acabados; } \\
\text { (b) estocagem de } \\
\text { insumos; } \\
\text { - (c) estocagem de } \\
\text { produtos acabados. }\end{array}$ \\
\hline Delta & $\begin{array}{l}\text { - Critérios ambientais não são } \\
\text { considerados sistematicamente. } \\
\text { - Melhorias pontuais no } \\
\text { desempenho ambiental dos } \\
\text { produtos, principalmente por } \\
\text { reação ao recrudescimento da } \\
\text { legislação ambiental e para } \\
\text { atendimento do mercado } \\
\text { externo. } \\
\text { - Adoção de fluídos refrigerantes } \\
\text { alternativos. }\end{array}$ & $\begin{array}{l}\text { - Critérios ambientais são } \\
\text { considerados sistematicamente. } \\
\text { - Tecnologias de final de } \\
\text { processo para o tratamento de } \\
\text { resíduos. }\end{array}$ & $\begin{array}{l}\text { - Critérios ambientais não são } \\
\text { considerados sistematicamente. } \\
\text { - Utilização da experiência prévia } \\
\text { obtida na gestão da qualidade } \\
\text { para liderar a gestão ambiental. } \\
\text { - Ferramentas da gestão da } \\
\text { qualidade não apoiam a gestão } \\
\text { ambiental. }\end{array}$ & $\begin{array}{l}\text { - Critérios ambientais } \\
\text { não são considerados } \\
\text { sistematicamente. }\end{array}$ \\
\hline
\end{tabular}

destaca-se a empresa Alfa, que apresenta continuidades e descontinuidades na inserção das questões ambientais nas práticas da produção, principalmente por não possuir procedimentos e diretrizes para tal, o que fica evidente na análise do processo de desenvolvimento de produto. Por fim, Beta e Delta apresentam um padrão não sistemático de inclusão da dimensão ambiental nas práticas produtivas e sem perspectivas para que esse quadro se altere.

\section{Conclusões}

Neste artigo, partindo-se de argumentos a favor da incorporação de temas sobre sustentabilidade ambiental na área de produção (Gunasekaran \& Ngai, 2012), realizou-se uma fundamentação teórica sobre 0 greening das principais atividades relacionadas à área produção/operações de empresas manufatureiras. Essa fundamentação pautou-se nos mais representativos 
estudos da área, como, por exemplo, Florida (1996) e Sarkis (2001), os quais, ainda que carentes de evidência empírica, forneceram um arcabouço teórico válido para contraposição à realidade observada em empresas localizadas no Brasil. A pesquisa empírica, realizada em quatro organizações, permite ressaltar que, de fato, as empresas vêm buscando implementar ações de gestão ambiental (Marcus \& Fremeth, 2009) e que a função produção é tida como fundamental para a gestão ambiental empresarial, confirmando a importância do tema (Gunasekaran \& Spalanzani, 2011). Entretanto, esse fenômeno empírico é mais complexo e menos linear quando comparado aos postulados da literatura especializada, devido aos meandros impostos pela realidade em que as organizações operam. Esse esforço de investigação buscou responder à questão de pesquisa declarada na introdução deste artigo, que foi respondida pela condução de quatro casos e cujas principais descobertas são descritas a seguir.

Nesse sentido, a primeira observação que deve ser registrada é que as organizações localizam-se em diferentes estágios da linha evolutiva da gestão ambiental (Barbieri, 2004).

Logicamente, a diferença entre as empresas com diferentes níveis de maturidade de gestão ambiental tende a se refletir no grau de incorporação das questões ambientais da função produção. Por exemplo, verificou-se que as empresas Beta e Delta, classificadas no estágio reativo da gestão ambiental, tendem a privilegiar atividades de gestão ambiental que contribuam para a redução de custos da atividade produtiva (Barbieri, 2004). Já a empresa Gama, classificada no estágio de gestão ambiental estratégica, possui um relacionamento mais avançado entre a gestão ambiental e as prioridades competitivas de qualidade e flexibilidade quando comparada com o padrão dos demais casos (Jabbour et al., 2012). Entretanto, não foi observada relação entre a prioridade de rapidez das entregas e a dimensão ambiental, o que merece ser analisado em estudos futuros.

Quando são lançadas luzes sobre as diferentes subáreas da função produção, duas conclusões merecem destaque: (a) o processo de desenvolvimento de produtos mostrou-se o mais pertinente, dentre todas as subáreas consideradas nesta pesquisa, para a avaliação da intensidade com que as questões ambientais são tratadas pela área produtiva; (b) a gestão da logística mostrou-se, para todos os casos analisados, a subárea da função produção em que as empresas apresentaram maior dificuldade para inserir a questão ambiental de forma mais apropriada. Essa constatação já havia sido acompanhada por trabalhos internacionais na área (Lai et al., 2013). A fraca incorporação da gestão ambiental nas atividades logísticas pode ser consequência da crescente terceirização logística, com foco geralmente predominante no baixo custo operacional e não na excelência em sustentabilidade. A reversão desse cenário requer que as empresas focais de cadeias de suprimentos comecem a adotar práticas de green supply chain management, exercendo, assim, pressão para que os demais elos da cadeia incorporem aspectos ambientais em suas atividades. Nesse sentido é importante também criar mecanismos e sistemas adequados para mensurar o impacto ambiental dos diversos modais de transporte (Lai et al., 2013), levando-se em conta a pressão que esses serviços sofrem para ter baixo custo. Com base nessas duas constatações é possível afirmar que a função produção tende a não incorporar a dimensão ambiental de forma homogênea no conjunto de suas atividades, como considera a literatura.

Inusitadamente, verificou-se que a função produção nos quatro casos analisados tornou-se um lócus propício para a formação de lideranças para a área de meio ambiente, uma vez que a trajetória de carreira dos responsáveis pela área ambiental perpassou, sistematicamente, o envolvimento em atividades relacionadas à função produção, tais como $\mathrm{P} \& \mathrm{D}$ e gestão da qualidade. Ainda nesse sentido verificou-se a experiência profissional na função produção para que esses funcionários ascendessem ao cargo de gerentes ambientais, o que reforça ainda mais o papel central da função produção para a criação da tão necessária cultura organizacional ambientalmente adequada (Fernandez et al., 2003) nas organizações sediadas no Brasil.

Os resultados desta pesquisa devem ser observados considerando-se suas limitações. Por exemplo, os resultados não podem ser extrapolados para além dos casos analisados. Além disso, sugere-se que em pesquisas futuras sejam analisadas as influências das pressões institucionais emergentes no esverdeamento da manufatura de empresas sediadas no Brasil, uma vez que a literatura vem apontando para a relevância dessas pressões (Zhu et al., 2005; Lai \& Wong, 2012), principalmente aquelas originárias dos países mais desenvolvidos e que podem afetar empresas manufatureiras de países ainda em desenvolvimento (Koh et al., 2012). Por fim, sugere-se que estudos vindouros desenvolvam e apliquem metodologias mais robustas para mensurar o desempenho ambiental de empresas manufatureiras, além de dedicarem-se ao esverdeamento dos transportes logísticos (Lai et al., 2013), área que sofre grandes pressões comerciais para manter baixos custos, o que certamente pode prejudicar o investimento em gestão ambiental. Para tanto, a experiência de trabalhos prévios que focam o setor de serviços pode servir como pano de fundo conceitual (Almeida \& Sellitto, 2013). 


\section{Referências}

Aboulnaga, I. A. (1998). Integrating quality and environmental management as competitive business strategy for 21 st century. Environmental Management and Health, 9(2), 6571. http://dx.doi.org/10.1108/09566169810211168

Almeida, T. S. M., \& Sellitto, M. A. (2013). Avaliação do desempenho ambiental de uma instituição pública de ensino técnico e superior. Produção, 23(3), 625-636. http://dx.doi.org/10.1590/S0103-65132012005000090

Angell, L. C., \& Klassen, R. D. (1999). Integrating environmental issues into the mainstream: an agenda for research in operations management. Journal of Operations Management, 17, 575-598.

Azzone, G., Bertelè, U., \& Noci, G. (1997). At last we are creating environmental strategies which work. Long Range Planning, 30(4), 562-571. http://dx.doi. org/10.1016/S0024-6301(97)00035-6

Backer, P. (2002). Gestão ambiental: a administração verde (2. ed.). Rio de Janeiro: Qualitymark.

Barbieri, J. C. (2004). Gestão ambiental empresarial. São Paulo: Saraiva.

Bayraktar, E., Jothishankar, M. C., Tatoglu, E., \& Wu, T. (2007). Evolution of operations management: past, present and future. Management Research News, 30(11), 843-871. http://dx.doi.org/10.1108/01409170710832278

Boiral, 0. (2002). Tacit knowledge and environmental management. Long Range Planning, 35, 291-17. http:// dx.doi.org/10.1016/S0024-6301(02)00047-X

Borchardt, M., Wendt, M. H., Sellitto, M. A., \& Pereira, G. M. (2012). Avaliação da presença de práticas do Design for Environment (DfE) no desenvolvimento de produto de uma empresa da indústria química. Produção, 22(1), 58-69. http://dx.doi.org/10.1590/ S0103-65132012005000001

Boudreau, J. W., \& Ramstad, P. M. (2005). Talentship, talent segmentation, and sustainability: a new HR decision science paradigm for a new strategy definition. Human Resource Management, 44(2), 129-136. http://dx.doi. org/10.1002/hrm.20054

Brío, J. A., Fernández, E., Junquera, B., \& Vázquez, C. J. (2001). Environmental managers and departmentos as driving forces of TQEM in Spanish industrial companies. International Journal of Quality \& Reliability Management, 18(5), 495511. http://dx.doi.org/10.1108/02656710110392638

Buchholz, R. A. (1998). Principles of environmental management. London: Prentice Hall.

Buysse, K., \& Verbeke, A. (2003). Proactive environmental strategies: a stakeholder management perspective. Strategic Management Journal, 24(5), 453-470. http:// dx.doi.org/10.1002/smj.299

Cauchick-Miguel, P. A. (2007). Estudo de caso na engenharia de produção: estruturação e recomendações para sua condução. Produção, 17(1), 216-229. http://dx.doi. org/10.1590/S0103-65132007000100015

Clark, K. B., \& Wheelwright, S. C. (1993). Managing New Product and Process Development. Free Press.

Corazza, R. 1. (2003). Gestão ambiental e mudanças da estrutura organizacional. Revista de Administração de Empresas (RAE-eletrônica), 2(2), 1-23.
Cunningham, J. B. (1997). Case study principles for different types of cases. Quality and Quantity, 31, 401-423. http:// dx.doi.org/10.1023/A:1004254420302

Daroit, D., \& Nascimento, L. F. (1998). A busca da qualidade ambiental como incentivo à produção de inovações. In: Encontro da Associação Nacional de Pós-Graduação e Pesquisa em Administração, Florianópolis.

Donaire, D. (1999). Gestão ambiental na empresa. São Paulo: Atlas.

Fernandez, E., Junquera, B., \& Ordiz, M. (2003). Organizational culture and human resources in the environmental issue: a review of the literature. International Journal of Human Resource Management, 14(4), 634-656. http:// dx.doi.org/10.1080/0958519032000057628

Florida, R. (1996). Lean and green: the move to environmentally conscious manufacturing. California Management Review, 39(1), 80-105. http://dx.doi.org/10.2307/41165877

Fuller, D. A., \& Ottman, J. A. (2004). Moderating unintended pollution: the role of sustainable product design. Journal of Business Research, 57, 1231-1238. http://dx.doi. org/10.1016/S0148-2963(02)00446-0

Ginsberg, J. M., \& Bloom, P. N. (2004). Choosing the right green marketing strategy. MIT SMR, 48, 79-85.

González-Benito, J., \& González-Benito, 0. (2006). The role of stakeholder pressure and managerial values in the implementation of environmental logistics practices. International Journal of Production Research, 44(7), 13531373. http://dx.doi.org/10.1080/00207540500435199

Gunasekaran, A., \& Ngai, E. W. (2012). The future of operations management: An outlook and analysis. International Journal of Production Economics, 135(2), 687-701.

Gunasekaran, A., \& Spalanzani, A. (2011). Sustainability of manufacturing and services: Investigations for research and applications. International Journal of Production Economics, 14O(1), 35-47. http://dx.doi.org/10.1016/j. ijpe.2011.05.011

Gupta, M. C. (1995). Environmental management and its impact on the operations function. International Journal of Operations \& Production Management, 15(8), 34-51. http://dx.doi.org/10.1108/01443579510094071

Handfield, R. B., Melnyk, S. A., Calantone, R. J., \& Curkovic, S. (2001). Integrating environmental concerns into the design process: the gap between theory and practice. IEEE Transactions on Engineering Management, 48(2), 18208. http://dx.doi.org/10.1109/17.922478

Hanna, M. D., Newman, W. R., \& Johnson, P. (2000). Linking operational and environmental improvement through employee involvement. International Journal of Operations \& Production Management, 20, 148-165. http://dx.doi.org/10.1108/01443570010304233

Hart, S. L. (1995). A natural-resource-based view of the firm. Academy of Management, 20(4), 986-1014.

Hervani, A. A., Helms, M. M., \& Sarkis, J. (2005). Performance measurement for green supply chain management. Benchmarking: an International Journal, 12(4), 330-353.

Hoffman, A. J. (2005). Climate change strategy: the business logic behind voluntary greenhouse gas reduction. California Management Review, 47(3), 21-46. http:// dx.doi.org/10.2307/41166305 
Hoppen, N., Lapointe, L., \& Moreau, E. (1996). Um guia para a avaliação de artigos de pesquisa em sistemas de informação. Revista Eletrônica de Administração, 2(2), 1-34.

Hunt, C. B., \& Auster, E. R. (1990). Proactive environmental management. Sloan Management Review, 31, 7-18.

Jabbour, C. J. C., Silva, E. M., Paiva, E. L., \& Santos, F. C. A. (2012). Environmental management in Brazil: is it a completely competitive priority?. Journal of Cleaner Production, 21(1), 11-22. http://dx.doi.org/10.1016/j. jclepro.2011.09.003

Jiménez, J. B. L., \& Lorente, J. J. C. (2001). Environmental performance as an operations objective. InternationalJournal of Operations \& Production Management, 21(12), 15531572. http://dx.doi.org/10.1108/01443570110410900

Kaebernick, H., Kara, S., \& Sun, M. (2003). Sustainable product development and manufacturing by considering environmental requirements. Robotics and Computer Integrated Manufacturing, 19, 461-468. http://dx.doi. org/10.1016/S0736-5845(03)00056-5

Koh, S. C. L., Gunasekaran, A., \& Tseng, C. S. (2012). Crosstier ripple and indirect effects of directives WEEE and RoHS on greening a supply chain. International Journal of Production Economics, 140, 305-317. http://dx.doi. org/10.1016/j.ijpe.2011.05.008

Kuehr, R. (2007). Environmental technologies. Journal of Cleaner Production, 15(13-14), 1316-1320. http:// dx.doi.org/10.1016/j.jclepro.2006.07.015

Lai, K., \& Wong, C. W. Y. (2012). Green logistics management and performance: Some empirical evidence from Chinese manufacturing exporters. Omega, 40, 267-282. http:// dx.doi.org/10.1016/j.omega.2011.07.002

Lai, K-H., Lun, V. Y. H., Wong, C. W. Y., \& Cheng, T. C. E. (2013). Measures for evaluating green shipping practices implementation. International Journal of Shipping and Transport Logistics, 5(2), 217-235.

Lawrence, L., Andrews, D., \& France, C. (1998). Alignment and deployment of environmental strategy through total quality management. The TQM Magazine, 10(4), 238245. http://dx.doi.org/10.1108/09544789810222603

Leonard-Barton, D. (1990). A dual methodology for case studies: synergistic use of longitudinal single site with replicated multiple sites. Organization Science, 1(3), 248266. http://dx.doi.org/10.1287/orsc.1.3.248

Lin, B., Jones, C. A., \& Hsieh, C. (2001). Environmental practices and assessment: a process perspective. Industrial Management \& Data Systems, 101(2), 71-79. http://dx.doi.org/10.1108/02635570110384348

Marcus, A., \& Fremeth, R. (2009). Green management matters regardless. Academy of Management Perspectives, 23(3), 17-26. http://dx.doi.org/10.5465/ AMP.2009.43479261

Martins, G., \& Nascimento, L. F. (1998). TQEM:A introdução da variável ambiental na qualidade total. In Simpósio de Gestão da Inovação Tecnológica, São Paulo.

Mross, D., \& Rothenberg, S. (2007). Formulating and implementing environmental strategies: A comparison of U.S. and German printing firms. Environmental Quality Management, 16(4), 55-68. http://dx.doi.org/10.1002/ tqem.20141

Novaes, A. G. (2001). Logística e gerenciamento da cadeia de distribuição. Rio de Janeiro: Campus.
Polizelli, D. L., Petroni, L. M., \& Kruglianskas, 1. (2005). Gestão ambiental nas empresas líderes do setor de telecomunicações no Brasil. Revista de Administração - RAUSP, 4O(4), 309-320.

Pujari, D., Wright, G., \& Peattie, K. (2003). Green and competitive: influences on environmental new product development performance. Journal of Business Research, 56, 657-671. http://dx.doi.org/10.1016/ S0148-2963(01)00310-1

Pun, K. P. (2006). Determinants of environmentally responsible operations: a review. International Journal of Operations \& Production Management, 23(3), 279-297.

Rao, P., \& Holt, D. (2005). Do green supply chains lead to competitiveness and economic performance? International Journal of Operations \& Production Management, 25(9), 898-916. http://dx.doi. org/10.1108/01443570510613956

Rohrich, S. S., \& Cunha, J. C. (2004). A proposição de uma taxonomia para a análise da gestão ambiental no Brasil. Revista de Administração Contemporânea - RAC, 8(4), 86-95.

Rothenberg, S., Pil, F. K., \& Maxwell, J. (2001). Lean, green, and the question for superior environmental performance. Production and Operations Management, 10(3), 228-243. http://dx.doi.org/10.1111/j.1937-5956.2001.tb00372.x

Rozenfeld, H., Forcellini, F. A., Amaral, D. C., Toledo, J. C., Silva, S. L., Alliprandini, D. H., \& Scalice, R. K. (2005). Gestão de desenvolvimento de produtos. São Paulo: Saraiva.

Russo, M.V., \& Fouts, P. A. (1997). A resource-based perspective on corporate environmental performance and profitability. Academy of Management Journal, 40(3), 534-556. http://dx.doi.org/10.2307/257052

Sarkis, J. (2001). Manufacturing's role in corporate environmental sustainability: concerns for the new millennium. International Journal of Operations and Production Management, 21(5-6), 666-686. http:// dx.doi.org/10.1108/01443570110390390

Sarkis, J., \& Rasheed, A. (1995). Greening the manufacturing function. Business Horizons, 17-27. http://dx.doi. org/10.1016/0007-6813(95)90032-2

Simpson, D. F., \& Power, D. J. (2005). Use the supply relationship to develop lean and green suppliers. Supply Chain Management: an International Journal, 10(1), 6068. http://dx.doi.org/10.1108/13598540510578388

Stone, L. J. (2000). When case studies are not enough: the influence of corporate culture and employee attitudes on the success of cleaner production initiatives. Journal of Cleaner Production, 8, 353-359. http://dx.doi. org/10.1016/S0959-6526(00)00037-8

Tingström, J., \& Karlsson, R. (2006). The relationship between environmental analyses and the dialogue process in product development. Journal of Cleaner Production, 14, 1409-1419. http://dx.doi.org/10.1016/j. jclepro.2005.11.012

Vachon, S., \& Klassen, R. D. (2007). Supply chain management and environmental technologies: the role of integration. International Journal of Production Research, 45(2), 401423. http://dx.doi.org/10.1080/00207540600597781

Voss, C., Tsikriktsis, N., \& Frohlich, M. (2002). Case Research in Operations Management. International Journal of 
Operations and Production Management, 22(2), 195219. http://dx.doi.org/10.1108/01443570210414329

Wu, H. J., \& Dunn, S. C. (1995). Environmental responsible logistics systems. International Journal of Physical Distribution \& Logistics Management, 25(2), 20-38. http://dx.doi.org/10.1108/09600039510083925

Zhu, Q., Sarkis, J., \& Geng, Y. (2005). Green supply chain management in China: pressures, practices and performance. International Journal of Operations \& Production Management, 25(5), 449-468. http://dx.doi. org/10.1108/01443570510593148

Zhu, Q., Cordeiro, J., \& Sarkis, J. (2013). Institutional pressures, dynamic capabilities and environmental management systems: Investigating the ISO 9000-Environmental management system implementation linkage. Journal of Environmental Management, 114, 232-242. http:// dx.doi.org/10.1016/j.jenvman.2012.10.006

\title{
Green manufacturing: from a conceptual background to multiple case studies
}

\begin{abstract}
The purpose of this paper is to analyze the integration of environmental issues in the context of manufacturing function/production (or operations), which is considered the organizational area that should lead corporate environmental management. We present a background on the greening of the manufacturing area, especially in terms of product development, process, quality management and logistics. Four case studies of Brazilian companies are presented as part of the study, and it is found that the maturity level of these companies' environmental management tends to follow the degree to which the environment has been inserted into subareas of production, especially in the process of product development. However, difficulties encountered in greening a company's logistics activities are also recognized in most cases. It is concluded that companies can overcome this challenge by adopting new concepts of green supply chain management. The notes highlight the observed distance between arguments in the international literature and the reality of Brazilian companies on the greening of manufacturing aspects.
\end{abstract}

\section{Keywords}

Environmental management. Manufacturing. Product development. Sustainability. 